\title{
Investigation of the Utilisation of Social Networks in E-learning at Universities
}

\author{
Sabah Azam ${ }^{1}$, Fang Wang ${ }^{1}$ \\ ${ }^{1}$ Department of Computer Science \\ Brunel University \\ Uxbridge UB8 3PH, UK \\ e-mail: fang.wang@brunel.ac.uk
}

\author{
Jason $\mathrm{Ng}^{2}$ \\ ${ }^{2}$ Etisalat BT Innovation Centre \\ Khalifa University of Science, Technology and Research \\ Abu Dhabi, United Arab Emirates \\ e-mail: jason.ng@bt.com
}

\begin{abstract}
Over the years universities have considered to use social networks for learning purposes as most of their students now engage on them. However, questions on the impact social networks would have on learning and how they can be utilised further for more effective teaching and learning are still unclear. To solve these questions, an in-depth investigation has been conducted to understand the benefits and drawback of social network features available for students. The investigation results show that students strongly believe that social network features will help enhance learning and the key ways of utilising such features have been suggested.
\end{abstract}

Keywords-E-learning, social networks, collaborative learning

\section{INTRODUCTION}

The growth and popularity of online social networks have created a new world of collaboration and communication. More than a billion individuals around the world are nowadays connected and networked together to contribute and share their knowledge and wisdom. Social networking is becoming evidently one of the most powerful tools for all generations to communicate, of which the typical examples are Facebook and Twitter.

Students at universities are also interacting constantly on the social networks with or without their lecturers' consent [1]. This allows students to discuss between each other individually and by groups, e.g., via the use of group chats and instant messaging, therefore resources other than what universities currently provide are being used to share knowledge and work through Internet without any restriction. This also shows that social networks are not being used for the stereotypical ways such as staying in touch with friends or to meet new people but they are now being used for many different purposes at free of cost.

Social networks exist everywhere around us, in workplaces, educational institutions as well as within families and social groups [2]. In fact, social networking is a concept that has been around much longer than the Internet or even mass communication and that people have always been social creatures [3]. As students are currently using online social networking sites where non formal ways of learning can be demonstrated, this illustrates that if universities utilise the features of the different online social networking sites into a new e-learning system it would help students learn in a more social and effective way and it would also help different individuals learn in their own unique way.

There has been an increase in attracting the attention of academic and industrial researchers intrigued by the affordances and reach of online social networks [4]. This has been shown through the huge amount of studies in this research area, however, a majority of the studies demonstrate that educational institutions adopt a specific social network such as Facebook into the organisation. Looking at previous studies it is evident that there is still a gap in this research about where universities can use social learning techniques and what features or aspects of the different social networks are suitable for building a new e-learning system. This paper aims to fill in this gap with considering student opinions and views to investigate the most appropriate aspects of social networks which the e-learning system should include and how they benefit the students.

\section{RELATED WORK}

Due to the expansion of technology, having it implemented for educational purposes changes the paradigm of the university. Elearning could be defined as electronic learning which consists of an acquisition of knowledge by using a computer and the use of Internet courseware [5]. An E-learning system is used as an information exchanging channel. E-learning services allow a wider horizon for organisations and individuals who are involved in teaching and learning, whereas traditional means of learning restrict certain learning methods due to time and place. According to [5], e-learning facilitates many sustainable parts of education to the learner and the teacher through the use of the tools and materials that can be accessed anytime and everywhere via many different devices that are web-based, web distributed or even webcapable, which therefore allows time to accelerate and leverage the rapid development and application of profound knowledge.

Social network sites is technology that enables users to connect with others by having personal profiles, allowing friends and colleagues to have access and compose messages to one another [5]. Using different social media also gives people the space for informal conversations and strengthening existing relationships, additionally to create new ones especially in learning as it gives students the chance to build relationships of comparable interest [6]. Even if they do not have much in common, their interests can be shared, which can help people engage and gain new interests. Social networks allow information to be distributed as blogging tools are used by many. This is distributed through one person posting information on a topic and others having the opportunity to re-post, share or even add their own additional information which can then continuously grow and help for learning purposes.

According to [6], the conversational, collaborative and communal characteristics of social media services are thought to reflect much of what is proven to be good types of learning as it transmits and maintains knowledge, which shows that students would benefit by enabling them to enter new types of collaborative learning according to their interests, as well as their immediate educational success, which has been demonstrated by Facebook as students build relationships. Therefore understanding the ways in 
which students use social networks allows a new system to facilitate many processes in e-learning.

Some educationists have welcomed the capability of social network services to provide teachers a forum for positive networking for students, which shows that some educational institutions have started to integrate the use of social networks for simple purposes such as conventional interaction and dialogue between students as well as instructors [7]. However the difference to their research and what this paper is researching is that they have implemented social networks such as Facebook [8] as part of their learning methods, instead of using it to help build a new system.

Social media such as Facebook and blogging have proven to result positive outcomes in learning and teaching as student engagement was proven to enhance communication [9]. This was the most valuable element of using the two social networks for learning as not only did this help students communicate with each other, it also helped the teacher engage with the students promptly. This shows a positive outcome on using the social networks, as students gradually became more confident with their work; it also allowed them to develop more skills as they had not previously had this type of learning.

On the other hand, it is clear that not all students are in favour of using social networks for learning purposes. Aaccording to [10], not all students agree with the use of social media being integrated with their learning. This is because they would prefer to keep their social roles and their student roles detached. This shows students have now become accustomed to using social networks for socialising as that is the main purpose of these sites and had been over the years, resulting to students becoming more reluctant to using these tools for educational purposes and may find it more of a distraction than a formal learning technique. Therefore considering this greatly it has highlighted that implementing social networks as a learning tool may not be the most suitable way in which learning is enhanced. This is the key strive of this research, as it investigates uses of social networks and the way they affect students.

\section{DATA COLLECTION}

Questionnaire and interviews have been used to collect student opinions to the use of social networking techniques in e-learning. An online questionnaire was produced and distributed to Brunel University students with 100 valid responses received. 10 university students had also been interviewed in order to obtain indepth understanding of students' behaviour and perceptions they have on social networks being used in universities. The interviewees include random 3-undergraduates $(2$ males and 1 female) and 7-postgraduates (5 females and 2 males).

\section{A. Questionnaire responses}

The questionnaire is composed of 14 questions in total, including 8 close-ended questions and 6 open-ended questions.

\section{Question 1: What is your Gender?}

Even though the questionnaire was distributed online to random students, $50 \%$ of each gender had responded. An equal percentage of each gender indicates the results of the following questions will not depended on gender.

Question 2: What is your age range?
As shown in Fig. 1, a wide range of different age groups had responded to the questionnaire $(16-21=31 \%, 22-25=42 \%, 26-31=$ $22 \%, 32-38=5 \%$ ). This clearly demonstrates that different ages have keen interest in the research topic, however it is particularly interesting in the sense that the results indicate that the overriding age range is that the of 22-25 year olds. This suggests the current age distribution in universities and the main interest on the use of online social networks for e-learning may be from the young generation.

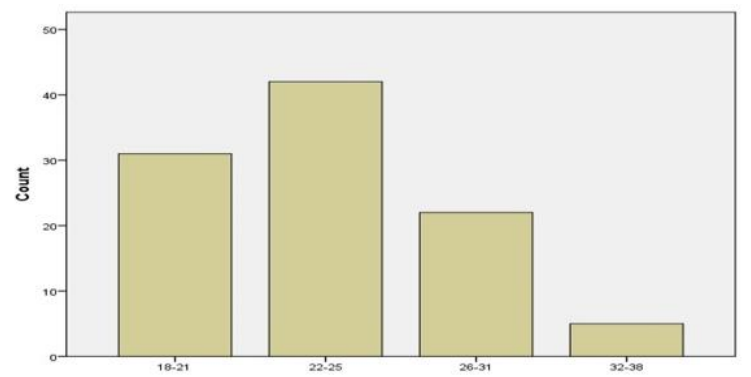

Fig. 1. Age Range

Question 3: How active are you on social media?

The results from this question indicate a largely positive response from the participants as it shows that $37 \%$ of them are 'very active' on social networks and around $29 \%$ echoed this by stating that they are 'active', as shown in Fig. 2. This shows by incorporating the idea of social network as part of learning, the system will be used by majority of the target audience, however it was of great interest that there was still a minority of respondents that are 'not active' or 'somewhat active' on social networks, therefore indicating that this still could be an issue as not everyone is using social networks.

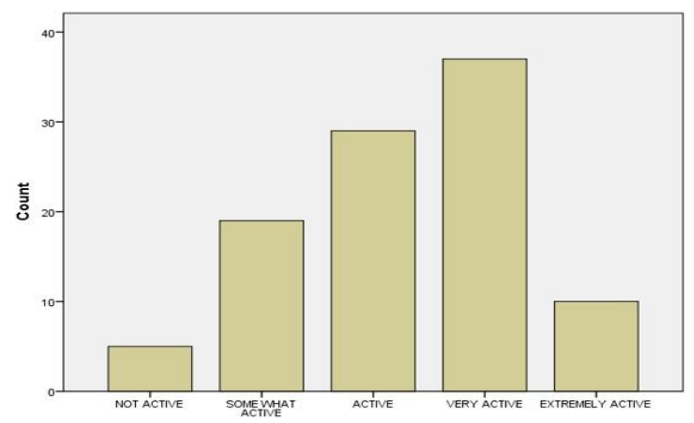

Fig. 2. Using Social media

Question 4: What do you use social media for?

As Table 1 shows the main purpose the participants use social media is mainly for entertainment as the results show the response rate at $38 \% .33 \%$ of respondents use social media for networking purposes. The result from this question indicates social media is used for many reasons, hence when being implanted into education, considerations would have to be made as to what are the values of such a system as entertainment will not be one for sure.

Question 5: What network would you prefer to use for learning purposes? And why?

This questionnaire was left as an open-ended question because of a wide range of social networks that are available to people, instead of narrowing down to specific option as there could have been potential participants that use different social networks that 
were not presented as an option. The results from the question shows that the majority of respondents would prefer Facebook to be the most appropriate network for learning at $46 \%$. The results also show that a wide range of options (e.g., Twitter, Google+, WhatsApp and Instagram) were mentioned as different participants had different views and reasons, however Facebook was one of the key answers that people believed was most appropriate because of the flexibility of the network.

TABLE 1. REASONS FOR USAGE

\begin{tabular}{|c|c|c|c|c|c|}
\hline & & Frequency & Percent & Valid Percent & $\begin{array}{l}\text { Cumulative } \\
\text { Percent }\end{array}$ \\
\hline \multirow{5}{*}{ Valid } & ENTERTAINMENT & 38 & 38.0 & 38.0 & 38.0 \\
\hline & NETWORKING & 33 & 33.0 & 33.0 & 71.0 \\
\hline & NEWS & 19 & 19.0 & 19.0 & 90.0 \\
\hline & $\begin{array}{l}\text { GENERAL } \\
\text { INFORMATION }\end{array}$ & 10 & 10.0 & 10.0 & 100.0 \\
\hline & Total & 100 & 100.0 & 100.0 & \\
\hline
\end{tabular}

Question 6: What key features from social networks do you currently use the most?

Looking at the results for this question shown in Table 2, it becomes apparent that all features of the options listed are used by the participants when using social networks with a $54 \%$ response. These results clearly indicate the importance of features on a social network as they are of main usage, however there is still a minority of users that use specific feature more than others.

TABLE 2. KEY FEATURES OF SOCIAL NETWORKS

\begin{tabular}{|cl|l|l|l|l|}
\hline & Frequency & Percent & Valid Percent & $\begin{array}{l}\text { Cumulative } \\
\text { Percent }\end{array}$ \\
\hline INSTANT & 16 & 16.0 & 16.0 & 16.0 \\
MESSAGING & 4 & 4.0 & 4.0 & 20.0 \\
HASH TAGS & 20 & 20.0 & 20.0 & 40.0 \\
Valid & GROUP CHATS & 6 & 6.0 & 6.0 & 46.0 \\
& LIKES & 6 & 54.0 & 54.0 & 100.0 \\
ALL THE ABOVE & 54 & 100.0 & 100.0 & \\
Total & 100 & \multicolumn{3}{|c|}{} \\
\hline
\end{tabular}

Question 7: If you had to choose one, what feature appeals to you the most to help learning for students?

The results from this question indicates a largely positive response from the participants as it clearly shows that the most appropriate feature that they would look for is 'group chats' as $68 \%$ responded. This illustrates that when considering the design of the learning system at university the most important feature would group chats, so that groups of students are able to communicate and discuss, this was not widely looked at in previously which helps this research understand what students look for on social sites. Nevertheless, some participants has chosen different options like 17\% 'instant messaging' and 7\% 'hashtags' these could also be of slight consideration as they were also chosen at a high percentage as Fig. 3. shows.

Question 8: What are the key features you would look for if social media was used for the purpose of student learning?

The pie chart in Fig. 4 shows that the majority of respondents would prefer a system that was able to provide them with 'constant updates'. This would be of great importance, when considering social networks for learning as results show that being updated on a constant basis is important to them, also the system being 'user friendly' is of some consideration as high volume of participants would prefer a system easy to use.

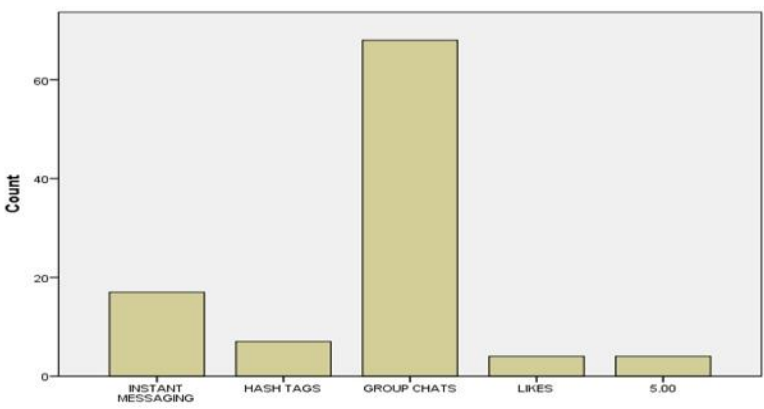

Fig. 3. Studying features

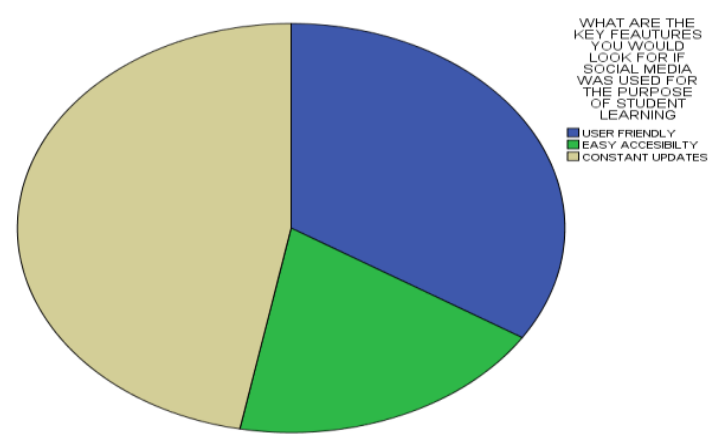

Fig. 4. Other features

Question 9: Do you believe that universities should use the same design/layout that the chosen social network in Question 5 uses?

The question was designed to understand the importance of the design/layout of the social networks that are used. The results of this question explain that a high majority of participants would prefer to use the same design/layout of their chosen social network (Fig. 5). This shows that if a university planned to implement a social based system majority of the students would want it to look as similar to the social network they used along with the same outline, even though a minority of students suggested they would not like the system to have the same design or layout, it could be of some consideration and can be explored further.

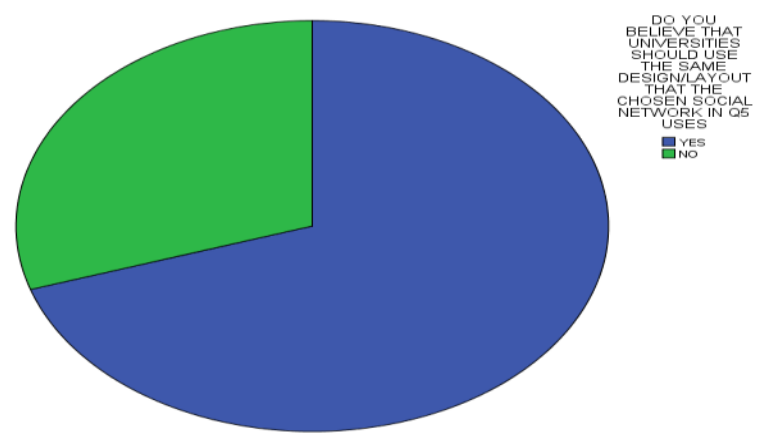

Fig. 5. Design/Layout

Question 10: If universities used social networks to help enhance learning would this help classroom engagement? And why?

This question was left open as it allowed participants to explain why they would or would not think that social networks would help enhance classroom engagement, from the result of this question it was clear that majority of respondents $81 \%$ believed that 'yes' it would help enhance learning greatly in classrooms, the respondents were also able to explain why and the key points that were continuously repeated was the fact that interaction between students online would help gain confidence as they would know 
their peers along with building strong relationships before classes This clearly shows that using social networks will have students more active and engaging than present times, however it was also shown that the minority of the respondents felt that it would be more of a distraction, it is a point to consider when implementing the network.

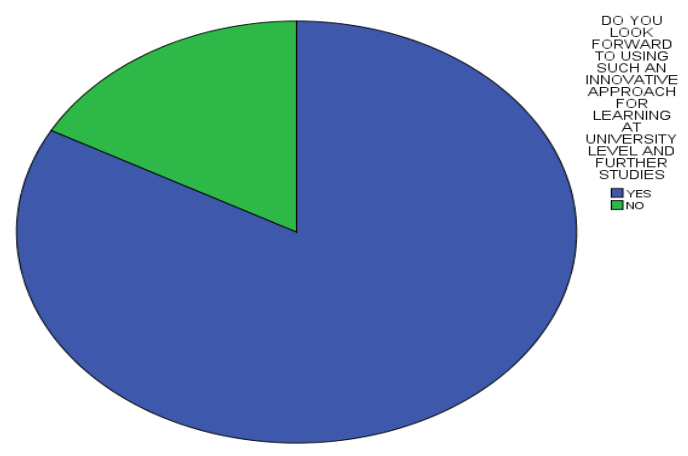

Fig. 6. Innovative Approach

Question 11: Do you believe that utilising social networking features can help build/strengthen social relationships for student? And why?

When implementing a more social based learning system it would be of great importance to include or even understand what features are used by students. It would be of interest of how they help build or even strengthen relationships because when at university working in groups and with others is a major way of learning. The results show $86 \%$ suggested that social network will definitely help encourage or strengthen relationships and the main reason of how it would help build relationships is because people currently are building relationships via social networks. They are also helping other to strengthen relationships as it is the most convenient way to keep in touch with one another. On the other hand, a small amount of respondents did not completely agree that it would help instead it would be more of a distraction.

Question 12: Is there anything that makes you reluctant to use a social based learning technique in the near future?

The decision of this question being open-ended was for the respondents to explain why if there was anything making them reluctant or why they would not, which would help understand specifically what the key issues are. From the results that are gathered it was clear that $48 \%$ of the respondent would be reluctant to use it because of 'hacking'. However, $47 \%$ of the respondents do not have anything that will stop them from using a social based learning technique. There was a small amount of respondent $(5 \%)$ that did not answer this question.

Question 13: Do you look forward to using such an innovative approach for learning at university and further studies?

Considering the results from the questionnaire, it has become apparent that using such an innovative approach for learning would be of great interest to the participants with $83 \%$ stating 'yes' to the approach, even though a minority $17 \%$ saying 'no', the result of participants agreeing to looking forward to using such an approach outweighs the negative.

\section{B. Interview responses}

Ten interview questions were designed when interviewing 10 random university students.

Question 1: What would be the most appropriate social network for the use of student learning and why?(e.g Facebook, Twitter, etc)

The reason for asking this question in the interview as well as the questionnaire was to allow comparison, which was done successfully, as the interviewee's response to this question was they would prefer 'Facebook', same as the questionnaire result. The most common reason from why they prefer Facebook was mainly due to the features and one in particular was the availability of using 'group chat'.

Question 2: Do you currently or have used social networks for studying purposes? If yes, How useful was it and what network? If no, why not?

Out of the 10 interviewees that took part in the interview had mentioned they have used social networks for study purposes and found it very useful as it was the most appropriate way to 'communicate with others' and 'ask questions to other students', which indicates that social networks have been successful in collaborating students together, even though two interviewees said they did not use any social networks primarily for studies. This question result shows that not all students merge social networking and studies together however they still use it to communicate with others generally.

Question 3: Do you think using a learning system like social networks will increase your learning productivity? If yes How? If no Why?

The results from this question clearly stated that student's productivity levels will definitely increase due to the flexibility of social networks. However, some interviewees showed concerns, in terms of productivity levels only increase 'if used correctly'. This shows there is to some level of uncertainties of using social networks due to the distraction it can create.

Question 4: Do you feel that a more social learning system can increase the quality of learning? If yes How? If no Why?

Even though question 3 and 4 are very similar, the response to this question was very interesting. Some interviewees showed that social networks to some degree will help the quality of work as it allows 'easier communication', however the other half of the interviewees showed more of a concern as 'getting the wrong information from others' and that the quality of work 'depends on the individual'. This indicates quality of student work may not be fully assessed through the use of social networks.

Question 5: If universities use social networks to enhance learning, do you believe that lectures should be engaging on this site or should it be mainly student orientated? And why?

The main reason for this question was to understand whether students prefer having some level of connection on social sites outside of university even though they can access them via email. The results to this question shows that half of the interviewees would want both students and lecturers to be engaging on the system as 'lecturers are a big part of the course' and 'lecturers should embrace what the students use' which would help both 
parties be up-to-date. However the other half did believe that it should mainly be students orientated as lecturers have their own ways to engage with student such as 'emails and office hours', suggesting that lecturers should stay 'traditional' to their classroom teaching.

Question 6: If universities use social networks to enhance learning, do you believe that lectures should be engaging on this site or should it If a new learning system was introduced what key features do you believe it would need that social networks use? How would it be useful? (e.g group chats, likes, etc)

This question was also asked in the questionnaire. In comparison to the questionnaire the results of the interviews were the same. The key feature preferred is 'group chats' along with it being user friendly, because it allows discussions and in relation to all the previous questions it is clear that it also helps greatly with communication with one another.

Question 7: Do you believe that the design or layout of the social network would be important? Should the similar layout of the social networks be used or different? How does this make an effect on students?

In response to this question all interviewees have expected a new layout and design of the new social learning technique. This is because the interviewees mentioned that if the layout was 'easily accessible and easy to use', it will encourage students to use it more as that's the main way in which students would use the system. In addition most interviewees chose Facebook as an example of the layout and design they prefer.

Question 8: Would students find it difficult to accept if a more social system was introduced or would it be more accepting as social networks are used already by many people? And why?

Most interviewees explained that they would not find it difficult to accept a new social system as most of them already use some kind of social network. Hhowever it is of great interest that some interviewees felt it may be difficult to accept as students may be 'resistant to change'.

Question 9: Is there any specific reason that would stop you from using a social networking website specifically for education and studies?

This question was also mentioned in the questionnaire; however the decision of including this in the interview was positive as the answers were very different. Most interviewees mentioned that they would not have much of a reason for not using such a site, however the key concerns that would arise would be 'if it was not used mainly for education' and 'getting the wrong information of students to use for revision'. These concerns are valuable when creating a system as if a learning system was introduced, students would want it to focus on their learning and not have additional features to distract them.

Question 10: Do you see a need for social networks being implanted at university for learning purposes? Why?

To end the interview it was interesting to note that not all interviewees find social networks being integrated at university is of any need, due to the other facilities universities have currently provided. However one interviewee suggested it is more of a 'want' from students, furthermore there was still a strong response of it being a need mainly due to the high use of technology and students using online sources much more.

\section{DISCUSSION}

The data collected in the last section provide resources for critical understanding of what features of online social networks can be used to enhance learning and how to improve the ways in which social networks are used to support learning for students, which is summarised below.

\section{A. The uses of social networks in learning}

The main purpose of this research was to discover ways universities can utilise social networks in learning, even though there have been many previous studies based on merging of social media in education, as discussed in Section II. It was clearly identified that there was missing research on how universities can use key elements from social networks to build a new e-learning system as an alternative to using an official social site.

Question 5 on the questionnaire proved that not much previous research has been conducted on social networks such as WhatsApp, Google, Instagram and many others, which illustrates this research has gathered useful information on what students currently use. From the results gathered Twitter was also highly recommended along with other networks like WhatsApp, Instagram, YouTube and LinkedIn, which shows that using elements from these sites could enhance the learning system. This is in contrast to previous research which suggested Facebook as the main choice. As stated by Frizell [11], 'Social media is like a disease that spreads, and then dies'. This indicates that choosing a specific social network for learning could cause a negative result in the future as eventually users of these networks will reduce and by having one main system for universities to embrace for learning will not be most.

In addition, question 2 on the interview explored what social networks are currently used by students because according to [1] students are currently using social networks with or without lecturers knowledge or consent. However results clearly show that not every interviewee uses social network for learning purposes, reasons for this was due to 'distraction' and 'merging social living with learning' together. Therefore this demonstrates that if universities implement social aspects to a university e-learning system, it should not be distracting and the key focus of the system should still be for learning along with students not feeling as if they do not have a separate life outside of learning.

\section{B. Features used on social networks}

As the majority of previous papers focused on a specific social network, it was a clear decision for this paper to concentrate on what key elements social networks provide could be used to implement on a new system. To investigate this further question 6 was demonstrated to understand the main features respondents currently use in their daily lives. Results showed that $54 \%$ respondents use all features available, however some respondents use specific features such as hashtags, instant messaging more than others which indicates that not all features are used equally. This was asked to help consider when designing a system as students would be able to have a system with multiple uses.

Following on question 7 was then produced to be more specific to what individuals would use for learning purposes. This was demonstrated to compare the features that are used from question 6 which suggested 'Group chats' was most important. 
Therefore, when designing a new system, the ability to have group discussions would be used more than other features. This was also proven via the interviews as responses confirmed that group chats is the most efficient features used for learning purposes.

In addition, question 8 identified that respondents prefer a system that would provide constant updates as a feature, which shows that students prefer being notified on new or recent events. However from the interview it was identified further that individuals also want a system that is user friendly and easily accessible. All of these features should be considered as each of these elements has a degree of importance when creating a new learning system.

\section{Student Engagement}

According to [9], social media such as Facebook and blogging have proven to result positive outcomes as student engagement was proven to enhance communication. From the questionnaire the results of question 10 showed a large sum of individuals believed it would help students to engage as online communication would help build confidence in students, which proves that having a social based system would encourage student engagement further. This could also relate to question 5 in the interview where students were asked whether the engagement of lecturers should be available or not and the response from this question did prefer lecturers to engage on the system, as valuable feedback from the interviews said 'lecturers are a key part of the course' and that 'lecturers should embrace what the students use' which would allow students to engage as they would be able to communicate before classroom sessions.

\section{Student Performance}

Question 3 in the interview examined whether students believed using social learning system would increase productivity, results showed a positive response due to the flexibility of working on an online system. However the concern for students using the system correctly was also mentioned. Therefore, when developing the new system, the idea of having distractions or inappropriate applications would need to be observed closely to make sure students are not able to abuse the system.

In addition, question 4 explored the impact social learning system would have on the quality of work. Responses showed mixed reactions as some students believed it would enhance quality where as others mentioned the possibility of getting wrong information and quality being dependent on each individuals working ability. This therefore indicates the quality of work students produce would not completely be measured through the use of the system as lecturers may not be part of some discussions and information can be misleading. However the opportunity to ask lectures via this system could resolve the concerns students have.

Furthermore, the results gathered from question 11 on the questionnaire proved that students believe the system would help/strengthen relationships, as that is the way they currently engage and build relationship. Othman also mentioned that due to informal and formal conversations on social media especially for learning, it gives the chance to build relationships [6]. This shows having a social system for learning could build more relationships at university which would be of great advantage as courses at university tend to last three years or more and having relationships with students would help them throughout the years. This would also help when doing group work as they would need to be able to communicate with different people and having built relationships will help efficient learning.

The above discussions demonstrate that a social networking based learning system at universities can help enhance student learning. Evidences from questionnaire and interviews prove that various possible aspects of social networks can be utilised at universities to enhance learning.

\section{CONCLUSIONS AND FUTURE WORK}

Even though social networking has been deemed to be useful for learning at universities, there is little research that has been done to understand what students would look for in a new social learning system. This paper has provided a detailed and in-depth investigation on student views and opinions via questionnaire and interviews. The results that have been gathered show that students would accept a social learning system however with the right uses. The research conducted in this paper provides deep understanding of the ways in which universities can use social networks and the key ways of utilising such networks was suggested through their features.

This paper investigated the views and opinion of students only due to time limitation. Further research could be done to include lecturers as well as other university staff, understanding how they feel about social learning systems. Different specific social network systems or platforms could also be studied, so as to provide more practical suggestions on the constructions social learning systems.

\section{ACKNOWLEDGMENT}

The authors are grateful to the anonymous reviewers for their insightful comments and constructive suggestions

[1] K. K. Khedo and et. al., "Case Studies on the Use of Online Social Networking informal Education," International Journal of Computer Applications, vol. 45, no. 8, pp. 21-26, 2012.

[2] J. Breslin and S. Decker, "The Future of Social Networks on the Internet. The Need for Semantics," IEEE Internet Computing, vol. 11, no. 6, p. 8690, 2007.

[3] A. Weaver and B. Morrison, "Social Networking," Computer, vol. 41, no. 2, pp. 97-100, 2008.

[4] N. B. Ellison and D. M. Boyd, "Social network sites: Definition, history, and scholarship," Journal of Computer-Mediated Communication, vol. 13, no. 1, 2007.

[5] J. Mahmood, H. M. Dahlan and A. Hussin, "Enhancement of e-learning system by using social network features," in IEEE Conference on $e$ Learning, e-Management and e-Services, 2013.

[6] W. Al-rahmi and M. Othman, "The Impact of Social Media use on Academic Performance among university students: A Pilot Study," Journal of information systems research and innovation, vol. 4, pp. 1-10, 2013.

[7] E. Maloney, "What Web 2.0 can teach us about learning," Chronicle of Higher Education, vol. 53, no. 18, p. B26, 2007.

[8] A. Nicole, "Social Networking in Undergraduate Education," Journal of Information, Knowledge, and Management, vol. 7, no. 1, pp. 63-90, 2012.

[9] M. Watts, "Richard Huish College: Facebook and Blogger - Using Social Media to enhance communication," [Online]. Available: http://www.jiscrsc.ac.uk/case-studies/sw/richard-huish-college-sw41.aspx. [Accessed 10 2014].

[10] D. Haytko and R. Parker, "Social networking tools in a university setting: a students perspective," Jurnal of Instructional Pedagogies, vol. 9, no. 1, pp. 1-9, 2012.

[11] S. Frizell, "Facebook Is About to Lose $80 \%$ of Its Users, Study Says," [Online]. Available: http://time.com/1405/facebook-is-about-to-lose-80of-its-users-study-says/. [Accessed 10 2014]. 